\title{
Be vigilant with your vocabulary
}

\section{Bróna Murphy}

As a linguist, I am always aware of moments in my day when I notice language playing a role in constructing and maintaining unequal relations between genders. The words we use delineate boundaries and can cast shade on how women, for instance, are represented and portrayed (Sigley \& Holmes, 2002; Baker, 2014). In a quick search of an online multi-million word database, I found that the most common words to appear alongside 'woman' include 'pregnant', 'dumpy', 'hysterical', 'old', 'married' and 'beautiful' whereas 'man' featured alongside 'right-hand', 'macho', 'sexiest', 'wise', 'good', 'great' and 'powerful'. Looking more closely at the word 'pregnant', it occurred in the following clusters: 'alone and pregnant', 'low and pregnant', 'large and pregnant', 'sick and pregnant', and 'single and pregnant'. Another search showed that while a 'bachelor' was 'eligible', a 'spinster' was 'elderly', and another search illustrated that while the word 'abrasive' can be used in 'abrasive coating', 'abrasive electronics', and 'abrasive blasting', it is also used to describe a female ('abrasive female') who has an irritating personality or is prone to causing friction or annoyance especially in the workplace. The adjective 'abrasive' does not occur with 'male'. For other examples, see Baker (2008) and Okimoto \& Brescoll (2010).

These patterns, which include a commentary on personal appearance and the negative portrayal of personality traits, show the kind of social asymmetry that can be found in language patterns, and how revealing language use is when gender is brought into the mix. My recipe is informed by inappropriate language use by a male colleague to describe my personal appearance when I was pregnant. This happened just as our pre-meeting chat was coming to an end and my colleague felt the need to comment on my increasing size by stating: "You're getting bigger by the day". This led to a somewhat awkward interaction where I, firmly but humorously, made him aware of the inappropriateness of his comment.

This recipe details how to raise awareness of inappropriate gender-related comments, in the workplace, in a non-confrontational way, while still getting your point across.

\section{Ingredients}

- An inappropriate gender-related comment from a colleague.

\section{Method}

1. Identify the gender bias: Take a moment to note the effect of the comment on you. How do you feel? Label your emotions: embarrassment, anger, self-consciousness, etc. Do you feel like retreating from the situation? Do you think you've misheard? Are you conscious of other people looking on? 


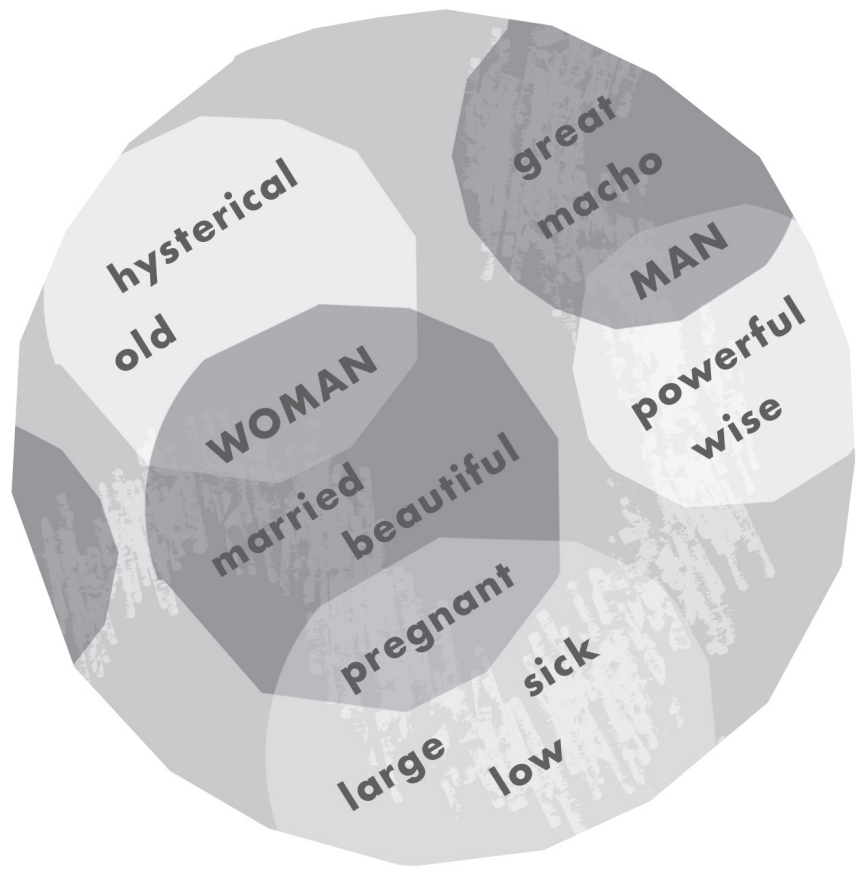

While it may be hard to define whether it is bias or not, you'll know how it makes you feel and that's enough to help you define it.

2. Gauge your colleague's intention. Was this comment intentional? Or was it a throw-away comment? This helps provide you with more context for understanding what has happened and what may be meant by the remark.

3. Rise above the bias: The bias says more about the other person than it does about you. Instead of reacting, take a moment to be fully mindful of the moment you find yourself in while you consider how you want to proceed (see the other flavour recipes for more on this). Consider the context (where you are, who else is there, age divide, closeness of work relationship, personality, hierarchy, etc.) as this will help you decide how to deal with it.

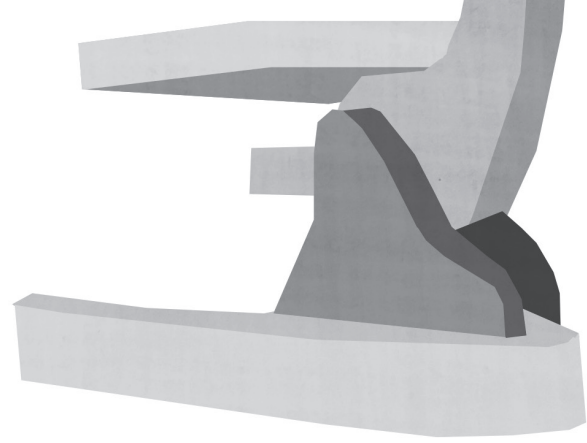


4. Address the issue: Make a decision to draw your colleague's attention to it immediately or wait until later when you can have a proper discussion. Humour is often useful in navigating potentially difficult situations as it de-escalates the threat of any confrontation while at the same time allowing you to navigate a potentially difficult situation with greater ease.

5. Dealing with the outcome 1: Your colleague may apologise for their insensitivity and the flippant comment, which was not ill-intentioned. Accept the apology and congratulate yourself for being linguistically aware enough to draw your colleague's attention to it. You'll have also done them a favour by perhaps making him more mindful of his language use in future.

6. Dealing with the outcome 2: However, your colleague may disagree that the comment was inappropriate. You may have a more complicated discussion on your hands. In this situation, you cannot force your colleague to understand your point if they fail to, or refuse to, but by addressing the issue, you'll have alerted them, on whatever level, to the fact that linguistic appropriateness exists whether or not they choose to accept it.

\section{Cook's tip}

If at all possible, it is best to avoid confrontation. By addressing the issue in a firm but respectful way, you are making your own point, and you are only responsible for you. You'll feel better having put your point across.

\section{Warning}

Your colleague may not take kindly to having their use of language highlighted. Be aware that you have the right to say how you feel whether they like it or not. 